\title{
China faces up to 'terrible' state of its ecosystems
}

\section{Wetlands hardest hit by land reclamation and pollution.}

\section{BY JANE QIU IN BEIJING}

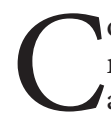
ounting the cost of decades of breakneck development, Chinese scientists and policy-makers last week outlined the daunting challenges they face in trying to halt the country's environmental degradation.

Government officials at the Symposium on Ecosystem Monitoring and Evaluation in Beijing promised to step up investment in ecological conservation and restoration over the next five years, although no precise details were given. Other delegates warned that the lack of a national long-term strategic plan for the environment, compounded by insufficient coordination among government sectors, could jeopardize such efforts.

"The ecological situation is terrible," admits $\mathrm{Xu}$ Jun of the Ministry of Science and Technology. More than a quarter of China's grasslands, for instance, have been lost to farming and mining activities in the past decade, and 90\% of the country's remaining 4 million square kilometres of grassland is in poor health. The grassland loss contributes to problems such as water shortages and sandstorms.

Coastal areas are under even greater pressure - from pollution, drainage and development. "Of all ecosystems, wetlands are the worst hit," says Yu Xiubo, an ecologist at the

\section{WETLAND THREATS \\ China's most endangered ecosystems are being degraded by factors linked to economic development. Unwise use of water resources $6.6 \%$

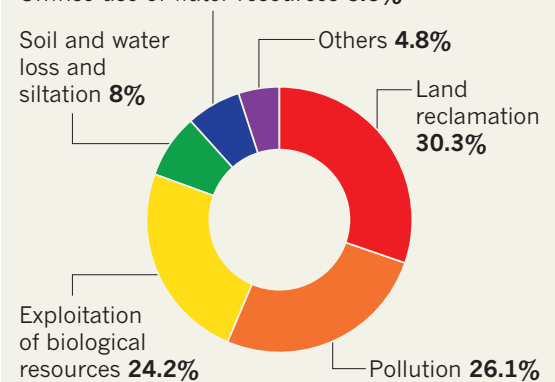

CHINA'S RESOURCES Percentage of world total

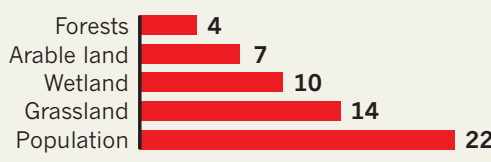

Beijing-based Institute of Geographic Sciences and Natural Resources Research, part of the Chinese Academy of Sciences (CAS).

A recent report by the China Council for International Cooperation on Environment and Development (CCICED), a joint Chinese and international advisory board to the government, shows that $57 \%$ of the country's coastal wetlands have disappeared since the 1950s, largely due to land reclamation (see 'Wetland threats'). Over the same period, the area covered by mangrove forests and coral reefs fell by $73 \%$ and $80 \%$, respectively.

On the basis of development projects approved by the government, the authors of the CCICED report estimate that another 5,800 square kilometres of coastal area will be lost by 2020 , eating away at the total 385,000 square kilometres of remaining wetlands.

\section{RECOVERY EFFORTS}

China has not ignored the problem. The forestry ministry has been mapping wetlands nationwide, and 2,538 nature reserves have been established covering about $15 \%$ of the country's total area, including half of the natural wetland ecosystems, according to Cui Lijuan, director of the Institute of Wetland Research in Beijing. However, nature reserves are often poorly protected from development.

Over the past five years, the science ministry has spent 500 million renminbi (US\$76 million) on the monitoring, evaluation and restoration of key ecosystems, says Xu. He says that funding will increase significantly, and will include a new focus on assessing the impact of pollution on public health. In collaboration with the CAS, the environment ministry will spend the next two years conducting a national ecological survey, following up on a survey done in 2000. Among the survey's goals are an assessment of the services provided by key ecosystems, and the impact of major engineering projects, including the Three Gorges Dam in central China.

According to Zhong Xianghao, an ecologist at the CAS Institute of Mountain Hazards and Environment in Chengdu, monitoring and restoring the fragile ecosystems of western China will be a priority. The government has earmarked

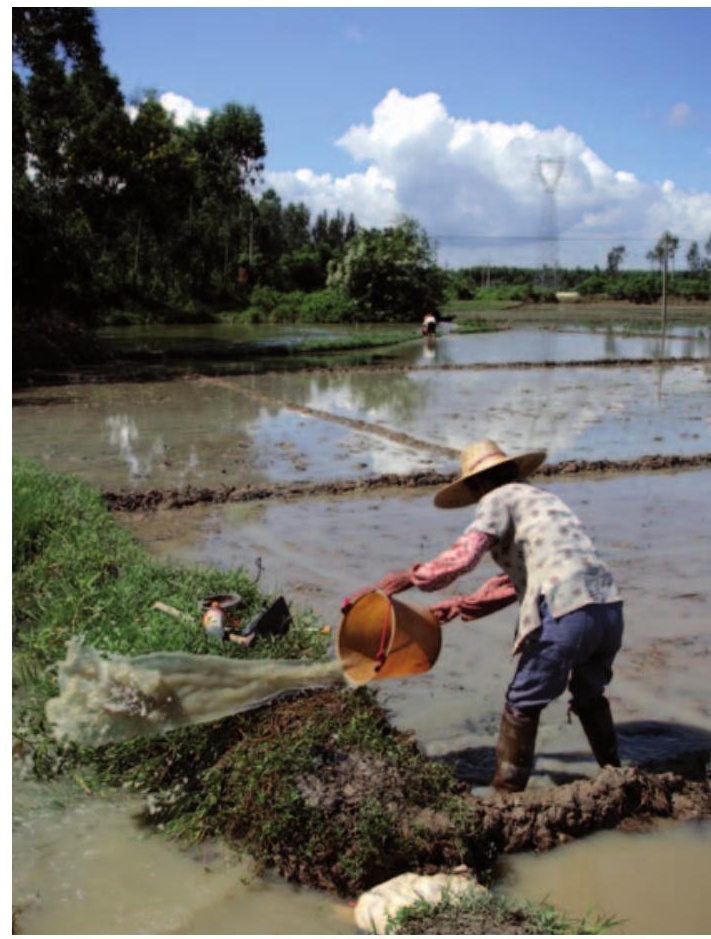

Goodbye mangroves, hello rice fields - but at what cost to China's ecological health?

15.5 billion renminbi between 2008 and 2015 for conservation projects and to create a monitoring network of ten ecological stations in the region. An additional 13.4 billion renminbi per year will be paid to farmers and nomadic peoples to conserve grassland in parts of western China, says Yang Zhi of the agriculture ministry.

Yet China will struggle to preserve its remaining intact ecosystems (see 'China's resources') in the face of the growing demand for land. This is being driven by population growth and by the government's plan to quadruple the country's gross domestic product between 2000 and 2020.

And some delegates at the symposium used the Chinese saying jiulong zhishui, meaning 'taming the water with nine dragons', to describe the overlapping monitoring efforts of various government ministries. These efforts are all too often short term and uncoordinated, says Cui, when "it takes decades to get a good idea of the baseline and changes of ecosystems". 


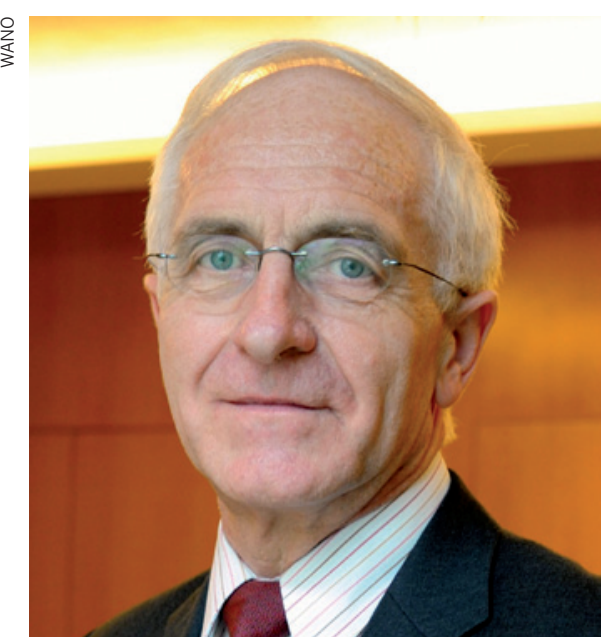

\section{Should Fukushima prompt WANO to change} its remit?

Until now, WANO has addressed lessons learned from reactor operations, but not reactor design issues. I think in the future it should, in particular so that when operators modify their designs they draw more on analyses of past accidents.

It is not easy to designate one reactor design as safer than another. Rather, one must look at the particular case of each reactor's implementation, and its location. A reactor exposed to the threat of a tsunami doesn't face the same risks as a reactor of the same design elsewhere.

Population proximity is also very important. Japan, like many other countries, has several enormous nuclear sites near dense populations, so those demand even higher safety margins. After Fukushima, I believe that safety reviews should also consider the risk of accidents at several reactors at the same site at the same time. Often the current plans are only done for an accident in one reactor at a site.

We also need to be prepared for events exceeding what a reactor was designed to withstand, and to learn how best to cope with accidents such as a loss of electricity supply and cooling capacity, as happened at Fukushima Daiichi. That means having the right emergency procedures and equipment, and regular emergency drills, often involving the local population. Some countries do this very well; others do it much less, or not at all.

Q\&A Laurent Stricker Nuclear safety chief
calls for reform

Laurent Stricker, chairman of the World Association of Nuclear Operators (WANO), says that the disaster at Japan's Fukushima Daiichi nuclear plant should mark a turning point for an industry that many experts believe has become complacent about the safety of its reactors. Created in 1989, WANO is an international forum, headquartered in London, that brings together all nuclear power plant operators, along with governments and nuclear experts, to improve operational safety across the industry. Stricker is a nuclear engineer and former power plant director, and is also the senior adviser on nuclear affairs to the French utility company EDF.

In October, WANO will bring together in China the chief executives of all the nuclear operators to discuss lessons learned from Fukushima, and any changes needed to WANO's mandate. WANO needs to be in a position to verify that every nuclear operating company has plans to cope with unforeseen accidents.

\section{Has the industry been overconfident that a} serious nuclear accident is now impossible? Absolutely. I worry about overconfidence. People think we have good designs, we have good operators, we have good procedures and good safety authorities, so they think everything is fine.

Does the International Nuclear Events Scale distort the true safety record of the industry, with 'near misses' being registered as lowlevel incidents rather than potential disasters? I think you are right. And it's true that the scale of severity is used in very different ways from one country to another. You also have differences in transparency from one country, and from one operator, to the next. At WANO, for example, we ask member companies to report incidents to us so that we can analyse them and share lessons from them. But between 5\% and $7 \%$ of the power plants don't report any events in a given year. As an operator, I'm convinced that anyone running a nuclear power plant is bound to have something to report over the course of a year.

\section{Could greater international oversight improve safety?}

My point of view is that there are not enough plans in place to immediately help an operator in another country to cope with an accident.

Also, for countries that are relatively new to operating nuclear power plants, peer review before plant start-up is essential because serious accidents have often occurred in new reactors shortly after start-up. WANO sends teams of 20-25 engineers from other nuclear plants to review the functioning of the new plant for about three weeks and to provide a confidential report. The International Atomic Energy Agency has a similar programme that does five or six similar reviews per year; WANO has greater resources and conducts about 40 of these reviews a year. At our meeting in China, I will propose increasing their frequency.

I have also proposed that if operators fail to make progress on issues flagged by these reports as 'areas for improvement', then WANO should be authorized to dispense with its obligations of confidentiality.

If there is another major accident, is nuclear energy finished?

I fear so. As we have seen at Fukushima, an accident in one country has consequences for all nuclear operators elsewhere.

\section{INTERVIEW BY DECLAN BUTLER}

(Edited and translated from French.)

\section{CORRECTIONS}

The news story 'China faces up to 'terrible' state of its ecosystems' (Nature 471, 19; 2011 ) stated that more than $25 \%$ of China's grasslands have been lost in the past decade. The percentage should have been $2.5 \%$

The Editorial 'Universal truths' (Nature 472, 136; 2011) should have referred to Joseph Greenberg, not Joshua Greenberg. 